\title{
Proximal migration of Plastibell circumcision: two case reports and review of the literature
}

\author{
Ali M. Ahmad ${ }^{1 *} \mathbb{B}$, Sara Elfadil Ahmed ${ }^{1}$, Noha Ali Mostafa² and Turki Ibrahim Nafisah ${ }^{1}$
}

\begin{abstract}
Background: Male circumcision is one of the oldest and most commonly performed surgical procedures in the world; in fact, one of every 3 males in the world is circumcised. Plastibell circumcision is the commonest procedure performed worldwide with higher rates of satisfaction and lower rates of complications.

Case presentation: We present two cases, 4 and 5 months old with proximal migration of Plastibell ring with penile incarcerations that were managed successfully. We aim to highlight the necessary precautions needed to avoid serious complications after a minor surgical procedure.

Conclusions: Plastibell circumcision is a minor surgical procedure that is underestimated with the potential for major and serious complications. The implementation of the law against the practice of non-professional individuals, standardization of the procedure, and improvement of communication are highly recommended to avoid unnecessary and serious complications. Plastibell ring circumcision still needs further studies to examine ring antimigration, re-designing, and the best types and sizes of threads used. Lastly, studies are also needed to determine a cost-effective routine follow-up visit post-Plastibell circumcision procedures.
\end{abstract}

Keywords: Circumcision, Plastibell, Migration, Complications, Penile incarcerations

\section{Background}

Male circumcision is one of the oldest and most commonly performed surgical procedures in the world; in fact, one of every 3 males in the world is circumcised. Plastibell circumcision is a commonly used procedure worldwide with higher rates of satisfaction and lower rates of complications [1-3].

We herein present two cases of proximal migration of Plastibell ring with penile incarcerations that were managed successfully. We aim to highlight the necessary precautions to avoid serious complications after a minor surgical procedure.

\footnotetext{
*Correspondence: aliahmed366@hotmail.com

${ }^{1}$ King Abdullah bin Abdulaziz University Hospital, Princess Norah Bint

Abdulrahman University, Airport Road, Riyadh, Saudi Arabia

Full list of author information is available at the end of the article
}

\section{Case report}

Two 4- and 5-month-old healthy infants presented to the emergency department, 2 weeks and 2 months, respectively, post-circumcision due to retained Plastibell ring and penile swellings. They did not complain of pain, urine retention, nor bleeding, and they showed a normal systemic review. Both patients presented with a firm and swollen glans penis due to the proximal migration of the Plastibell ring (Figs. 1 and 2). Under local anesthesia, using penile ring block ( $2 \mathrm{ml}$ of lidocaine $1 \%$ ), we cleaned the operation field, applied a lubricant around the plastic ring, and cut it at the dorsal side of the penis with a strong pair of stitch scissors. After safe removal of the Plastibell ring, we re-examined the penis and found no urethral injuries, no skin defects, but there was only a circumferential penile sulcus with red mucosa on the distal penis secondary to pressure effects of the ring. Follow-up after 2 weeks and after 1 month showed improvements in glans swelling, good cosmetic outcomes, and no urinary complaints. (Fig. 2). 

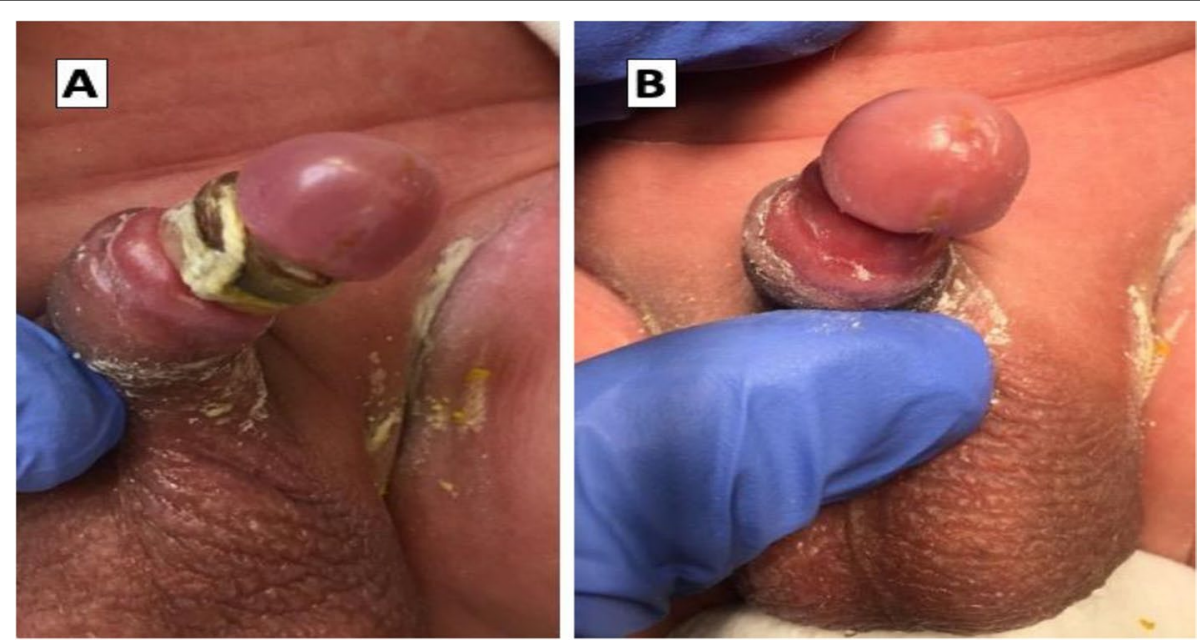

Fig. 1 Four-month-old child: A 2 weeks post circumcision show a proximal migration of Plastibell with its constriction effect with swelling in the glans penis and $\mathbf{B}$ immediately after Plastibell removal

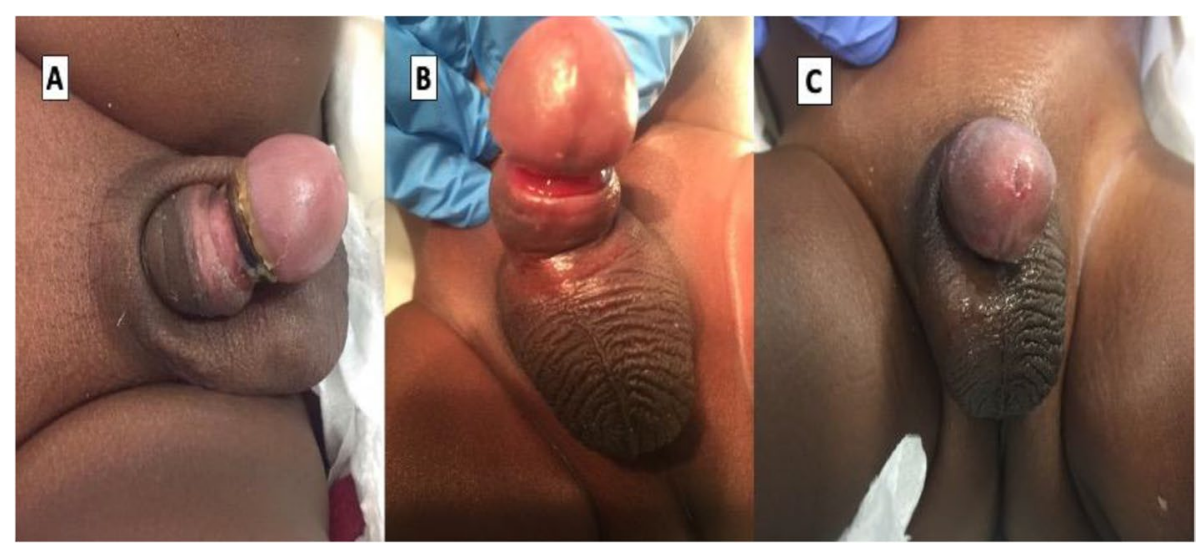

Fig. 2 Five-month-old child: A 2 months post-circumcision show a proximal migration of Plastibell with swelling in the glans penis, B immediately after Plastibell removal, and $\mathbf{C} 2$ weeks after Plastibell removal with a good cosmetic outcome

\section{Discussion}

In 2012, the American Academy of Pediatrics issued a policy statement in which it concluded that the benefits of male circumcision outweigh the procedure's risks [4]. The Plastibell circumcision tool was introduced by Hollister in 1950. It is safe and easy to perform and has become one of the most commonly used procedures worldwide with higher rates of satisfaction and lower rates of complications, especially for children below 2 years $[5,6]$.

Plastibell device is a clear protective plastic ring that shields the underlying glans penis from the scalpel. The ring comes in different sizes and has a deep groove running circumferentially and a cotton thread is usually included in the pack which obviates bleeding through a strangulating suture tied over the non-yielding plastic ring left in place at the corona. The Plastibell ring usually falls within a week or two $[1,6]$.

Plastibell circumcision is categorized as a minor surgical procedure even though it deals with the penis, which is an important multifunction organ. Moreover, during infancy, it is small in size which subjects it to many complications following circumcision such as bleeding, localized infection, excessive loss of the skin, inadequate skin removal, incomplete separation of Plastibell device, catastrophic complete glans autoamputation, and proximal relocation of the ring with prolapse of the glans over the ring like our presented cases [1, 7]. Unfortunately, circumcision is an underestimated procedure that needs standardization to prevent its complications. 
Circumcision is performed not only by urologists, pediatric surgeons, general surgeons, family physicians, pediatricians, and gynecologists, but also by non-qualified people, barbers, technicians, and others. Each works by different criteria and standards. In some areas of the world, circumcision is sometimes considered a procedure that may be performed without even having basic surgical knowledge. This has resulted in many deaths and serious long-term complications [8]. Therefore, the law against the practice of circumcision by untrained and unregistered people should be implemented seriously to avoid medical malpractice in the twenty-first century.

A clear understanding of the procedure, post-operative care instructions, and red flag symptoms or signs that may lead to the patient's return to the hospital are the information needed for efficient communication. Translation services may be necessary when a language barrier is present [9]. Parents of the patients expressed a preference for physicians who took patient-family education seriously because it could decrease the incidence of avoidable complications [4]. In our 2nd case, the parents did not notice that the transparent Plastibell was still retained since the patient was asymptomatic. The presence of a language barrier led to the patient's delayed presentation 2 months later. The patient was lucky that no catastrophic complications occurred in his incarcerated glans penis.

Like our hospital, most institutes do not provide a routine post-circumcision follow-up visit and usually, the circumcised babies are sufficiently inspected by the parents for complications until the ring falls off 3 . We believe that if a routine follow-up visit had been given to our patients, it may have prevented these complications. We recommend a further study to test for the cost-effective needs/benefits of a routine follow-up visit 7-14 days after circumcision.

Plastibell ring is expected to fall off in 5-7 days, completing the process of circumcision. The ring separates faster in younger children due to thin prepuce and easier sloughing. Plastibell impaction rate for children over 1 year was more than seven times the rate observed for children aged 1 year or less [5]. These results emphasize the importance of the Plastibell technique in infancy. However, further studies are needed to determine the best circumcision techniques for older children.

The Plastibell comes in 7 sizes $(1.1$ to $1.7 \mathrm{~cm})$, an appropriate size should fit the glandular cone without riding up to the corona or beyond. The size is usually selected by a visual estimate of the glans girth which gets better with practice and experience. Undersized and oversized rings may result in tissue necrosis as well as retained Plastibell and proximal ring migration, respectively $[3,5,6]$. Bode et al. (2010) suggested a redesign of the Plastibell to incorporate an anti-migration component of the distal portion by its molded as a cone 3.

The long period of a non-separated ring is associated with an increased risk of proximal migration. A study performed by Altokhais et al.(2019), on 200 patients found that those who were circumcised using Plastibell tied by Polypropylene 0 instead of the classic cotton thread resulted in their Plastibell falling faster [10]. This study will open the door for further studies to examine the best types and sizes of threads used in Plastibell circumcision.

\section{Conclusion}

Plastibell circumcision is a minor surgical procedure that is underestimated with the potential for major and serious complications. The implementation of the law against the practice of non-professional individuals, standardization of the procedure, and improvement of communication are highly recommended to avoid unnecessary and serious complications. Plastibell ring circumcision still needs further studies to examine ring antimigration, redesigning, and the best types and sizes of threads used. Lastly, studies are also needed to determine a cost-effective routine follow-up visit post-Plastibell circumcision procedures.

\section{Acknowledgements \\ N/A}

\section{Authors' contributions}

AM was responsible for the production of the manuscript. SA contributed to the data collection and writing of the manuscript. NA and TN contributed to the writing and review of the manuscript. The author(s) read and approved the final manuscript.

\section{Funding}

No funding

Availability of data and materials

Available from the corresponding author upon request.

\section{Declarations}

Ethics approval and consent to participate

Verbal consent was obtained from the parents for publication as there is no any personal information that could lead to the identification of the patients.

\section{Consent for publication}

We did not apply for IRB approval because we believe that the case report does not contain any personal information or administration data, but if it is still mandatory, please let us know so we will apply for IRB.

\section{Competing interests}

The authors declare that they have no competing interests.

\section{Author details}

${ }^{1}$ King Abdullah bin Abdulaziz University Hospital, Princess Norah Bint Abdulrahman University, Airport Road, Riyadh, Saudi Arabia. ${ }^{2}$ College of medicine, Ain Shams University, Cairo, Egypt. 
Received: 10 May 2021 Accepted: 6 October 2021

Published online: 03 January 2022

\section{References}

1. Bawazir OA. A controlled trial of Gomco versus Plastibell for neonatal circumcisions in Saudi Arabia. Int J Pediatr Adolesc med [internet]. 2020;7(3):132-5. Available from. https://doi.org/10.1016/j.jpam.2019.03. 002.

2. Prabhakaran S, Ljuhar D, Coleman R, Nataraja RM. Circumcision in the paediatric patient: a review of indications, technique and complications. J Paediatr Child Health. 2018:54(12):1299-307.

3. Bode CO, Ikhisemojie S, Ademuyiwa AO. Penile injuries from proximal migration of the Plastibell circumcision ring. J Pediatr Urol [Internet]. 2010;6(1):23-7. Available from:. https://doi.org/10.1016/j.jpurol.2009.05. 011.

4. Malm-Buatsi E, Anderson AGS, Gubbins E, PagePhillips E, Maizels M, Washington KT. A qualitative study of parental preferences for postcircumcision care education. J Pediatr Urol. 2020;16(1):46.e1-46.e6. Available from: https://doi.org/10.1016/j.jpurol.2019.10.010.

5. Hammed A, Helal AAE, Badway R, Goda SH, Yehya A, Razik MA, et al. Ten years experience with a novel modification of plastibell circumcision. African J Paediatr Surg. 2014;11(2):179-83.
6. Jimoh BM, Odunayo IS, Chinwe I, Akinfolarin OO, Oluwafemi A, Olusanmi EJ. Plastibell circumcision of 2,276 male infants: a multi-Centre study. Pan Afr Med J. 2016:23:1-9.

7. Hosseini J, Haghdani S, Narimani N. Glandular amputation by strangulating tied suture: a case report of late-onset complication in the Plastibell circumcision technique. BMC Pediatr. 2019;19(1):4-7.

8. Samad A, Khanzada TW, Kumar B. Plastibell circumcision: a minor surgical procedure of major importance. J Pediatr Urol [Internet]. 2010;6(1):28-31. Available from:. https://doi.org/10.1016/j.jpurol.2009.05.006.

9. Otto R, Evans G, Boniquit C, Peppas D, Leslie J. Why desired newborn circumcisions are not performed: a survey. Urology [Internet]. 2016;97:18893. Available from: https://doi.org/10.1016/j.urology.2016.06.054

10. Altokhais T, Elsarrag A, Khan S, Alshehri A, Albassam A. Neonatal plastibell circumcision: does the thread type matter? A prospective randomized study. J Pediatr Urol. 2019;15(5):562.e1-562.e5. Available from: https://doi. org/10.1016/j.jpurol.2019.07.015.

\section{Publisher's Note}

Springer Nature remains neutral with regard to jurisdictional claims in published maps and institutional affiliations.

\section{Submit your manuscript to a SpringerOpen ${ }^{\circ}$ journal and benefit from:}

- Convenient online submission

- Rigorous peer review

- Open access: articles freely available online

- High visibility within the field

- Retaining the copyright to your article

Submit your next manuscript at $\boldsymbol{\nabla}$ springeropen.com 